\title{
IPO-UNDERPRICING:
}

\section{REPUTASI UNDERWRITER DAN TINGKAT PENGEMBALIAN \\ OPERASI ASET}

\author{
Ari Purwanti \\ Universitas Dian Nusantara
}

\begin{abstract}
The condition of underpricing at the time of the initial public offering (IPO) on the Indonesian stock exchange which is influenced by the rate of return on assets and the reputation of the underwriters is the purpose of this research. There are 84 companies used as research samples from 159 companies that experienced underpricing conditions during the period 2015 to 2019 on the Indonesia Stock Exchange. By using multiple linear regression in the hypothesis testing method, this study proves that the underwriter's reputation and the rate of return on assets have a negative effect on the underpricing condition. This empirical result shows that companies with higher asset performance and using reputable underwriters are proven to reduce underpricing conditions at the time of the IPO.
\end{abstract}

Keywords: Underpricing, Return on Asset, Reputable Underwriters

\section{PENDAHULUAN}

Keputusan untuk memperoleh dana dari pasar modal merupakan sinyal awal kepada publik bahwa perusahaan sedang mengalami pertumbuhan yang membutuhkan dukungan besar dari publik (investor potensial). Penawaran saham perdana (IPO) merupakan langkah besar perusahaan yang menangani bisnis yang semakin berkembang, setelah menjaga komitmen tingkat hutang yang aman bagi perusahaan (Pennacchio, 2014). Diversifikasi investasi pun dilakukan untuk meningkatkan modal ekuitas dari publik (Mumtaz, et al., 2016). Harapan pasar akan reaksi positif pada harga saham saat hari terjadinya IPO merupakan keinginan dari para emiten. Sehingga, adanya fenomena harga saham pada pasar perdana (IPO) lebih rendah dibandingkan dengan harga saham pada pasar sekunder pada hari pertama menjadi fenomena umum yang terjadi. Kondisi ini disebut underpricing (Reiche, 2015).

Asumsi underpricing akan menjadi ideal saat penentuan harga saham perdana memang efisien. Adanya asimetri informasi membuat underwriter berada pada posisi yang memiliki informasi lebih banyak tentang perusahaan dibandingkan investor, bahkan dibandingkan dengan emiten sekalipun. Kondisi asimetri informasi menimbulkan konflik kepentingan antara underwriter sebagai agent dengan emiten sebagai principial (Chhabra, et al., 2017). Padahal, perusahaan menggunakan jasa underwriter dalam rangka menjembatani proses arus informasi (melalui penerbitan prospektus) agar investor potensial memiliki informasi yang memadai tentang emiten.

Anomali underpricing tersebut telah menarik minat akademisi, peneliti, dan praktisi selama beberapa dekade. Banyak peneliti mencoba menjelaskan tingkat underpricing di berbagai negara serta di berbagai periode waktu yang berbeda (Loughran dan McDonald, 2013; dan Afza, et al., 2013). Untuk pasar bursa di negara Asia khususnya, Moshirian, et al. (2010) membuktikan bahwa tingkat underpricing pasar bursa di negara-negara Asia lebih tinggi dibandingkan pasar bursa di luar 
negara-negara Asia. Kondisi ini memberikan sinyal bahwa pasar mengapresiasi kinerja perusahaan dengan memberikan harga yang lebih tinggi dari harga penawaran perdana. Kondisi underpricing ini pun dialami pada pasar bursa Indonesia (BEI) (Gumanti, et al., 2017). Pada periode 2015 sampai dengan 2019 seperti yang tampak pada Gambar 1 menggambarkan kondisi underpricing yang terjadi di BEI pada emiten yang IPO selama 2015 sampai dengan 2019. Terlihat anomali underpricing tidak penah kurang dari $88 \%$ setiap tahunnya.

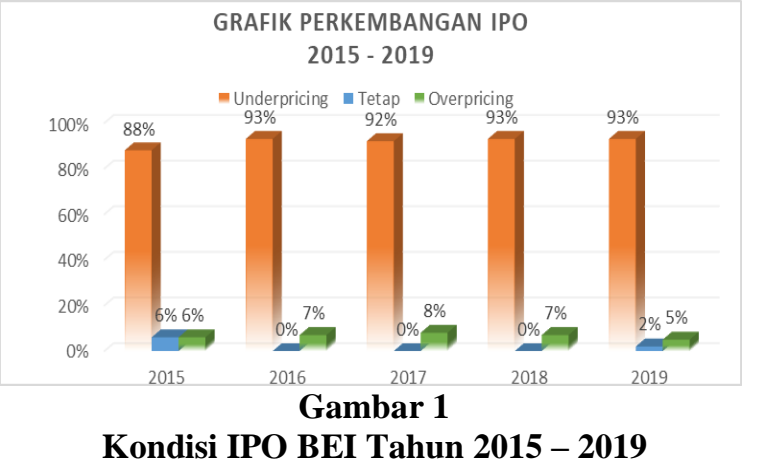

Saat IPO, pasar (investor potensial) cenderung tidak memiliki informasi yang memadai tentang perusahaan yang melakukan IPO. Masalah asimetri informasi pun muncul sebagai keraguan investor potensial untuk pengambilan keputusan (Leland dan Pyle, 1977). "Lemon Problem" seperti apa yang diungkap Akerlof (1970) dapat menjadi kendala serapan informasi bagi investor potensial. Tingkat pengembalian laba atas operasi aset yang tinggi sepertinya masih menjadi cerminan bahwa perusahaan telah dikelola dengan baik dan menguntungkan. Namun, apakah informasi ini cukup membuat investor potensial memiliki keyakinan yang memadai untuk pengambilan keputusan, seringkali menjadi masalah berikutnya. Untuk itu, keberadaan perantara keuangan (perusahaan sekuritas) dibutuhkan sebagai jembatan informasi antara emiten dan investor potensial, sekaligus sebagai penjamin emisi efek (underwriter).
Perantara keuangan yang biasanya adalah perusahaan sekuritas yang memiliki ijin penjamin emisi efek (underwriter) haruslah meyakinkan investor potensial atas emisi efek dari emiten (McDonald dan Fisher, 1972 dan Loughran dan Ritter, 2002). Di sinilah reputasi underwriter dibutuhkan agar saat penawaran saham perdana, saham perusahaan yang melakukan IPO memiliki jaminan dari pihak ketiga atas informasi yang dikeluarkan oleh perusahaan dalam emisi sahamnya (Chen, et al., 2013). Reputasi underwriter merupakan sinyal yang mencerminkan kualitas penjamin emisi (Dai, et al., 2014).

Underwriter dengan kualitas yang baik akan membuat prospektus perusahaan emiten sesuai dengan kondisi pencapaian kinerja emiten. Sehingga, anomali underpricing bukanlah fenomena oportunistik dari underwriter, yang mengupayakan hanya sebagai keberhasilan underwriter membuat harga saham menjadi lebih besar dari harga saham perdananya, dengan menetapkan harga perdana yang rendah. Sehingga, seolah-olah pasar mengapreasiasi emiten dengan harga yang lebih baik setelah melihat return on assets yang positif. Dengan latar belakang fenomena tersebut, penelitian ini berusaha untuk menyelidiki bagaimana pengaruh kinerja internal perusahaan dalam mencapai tingkat pengembalian aset dan kinerja eksternal dari reputasi underwriter terhadap tingkat underpricing yang dialami perusahaan-perusahaan yang tercatat mengalami underpricing pada saat IPO di BEI. Hasil penelitian ini diharapkan dapat memberikan kontribusi pada profesi underwriter sebagai pihak perantara antara emiten dan investor dalam peran dan peningkatan kinerja dan reputasinya. Sekaligus dapat memberikan kontribusi pagi emiten untuk tetap mempertimbangkan penetepan harga yang optimal saat penawaran harga saham perdana berdasarkan 
tingkat pengembalian aset yang optimal saat IPO sebagai cermin kinerja perusahaan.

\section{LANDASAN TEORI}

Beberapa teori dasar yang digunakan dalam penelitian yang menjelaskan kondisi underpricing pada saat IPO adalah teori Informasi Asimetris (dikemukakan oleh Akerlof (1970); Signaling Hypothesis (Leland dan Pyle, 1977); Teori Keagenan (Jensen and Meckling. 1976); Theory of Prestigious Underwriter, Window of Opportunity Hypothesis (McDonald dan Fisher, 1972); dan Teori Prospek (Loughran dan Ritter, 2002).

Fenomena yang terkait dengan initial return yang positif pada hari perdagangan pertama IPO, yang dikenal sebagai underpricing, telah didokumentasikan secara luas di hampir setiap pasar keuangan di seluruh dunia (Lowry, et al., 2017; Loughran dan McDonald, 2013; dan Afza, et al., 2013) dan penelitian secara khusus regional Asia oleh Moshirian, et al. (2010). Adanya aksi penetapan tingkat harga saham perdana yang rendah pada saat IPO (Ritter dan Welch, 2002) membuat kondisi underpricing dinilai sebagai keberhasilan dan kualitas IPO menurut emiten dan underwriter.

Investor potensial yang kurang memiliki informasi biasanya menghadapi risiko ketidakpastian yang lebih tinggi karena terbatasnya jumlah informasi yang tersedia bagi mereka sebelum IPO. Asimetri informasi membuka peluang bagi emiten dan underwriter untuk menetapkan harga yang rendah saat penawaran harga saham perdana (Rock, 1986 dan Beatty dan Ritter, 1986).

Penetapan harga yang rendah pada saat IPO tidak terlepas dari dasar perhitungan awal dengan memperlihatkan laba operasi atas aset perusahaan yang positif (Ritter dan Welch, 2002). Asumsinya, laba operasi aset yang positif menunjukkan bahwa perusahaan telah dikelola dengan optimal dan untuk berkembang membutuhkan dukungan tambahan modal. Namun, pada tingkat laba berapa secara persisnya merupakan risiko yang dihadapi investor potensial karena kekurangan informasi emiten.

Bila merunut pada signalling theory (Leland dan Pyle, 1977), kondisi kinerja perusahaan yang menghasilkan laba operasi aset yang lebih tinggi akan berfungsi sebagai good news bagi pasar, sehingga pasar diharapkan mengapresisasi prestasi emiten tersebut. Tandanya adalah keberhasilan kenaikan harga saham sampai pada harga penutupan (Loughran dan Ritter, 2002) Yang berarti iniatial return saat IPO akan positif (kondisi underpricing). Namun, bila merunut pada teori asimetri informasi pada "lemon problem" yang diungkap Arkelof (1970), laba operasi aset yang tinggi dapat terlihat menjadi pemanis, sehingga investor potensial justru malah kurang mengapresiasi hasil kinerja perusahaan dalam menghasilkan laba. Jadi, meskipun initial returnnya positif, namun tingkat underpricingnya boleh jadi tidak sebesar situasi investor potensial mengapresiasi laba operasi aset perusahaan. Berangkat dari pertimbangan tersebut, penelitian ini mencoba membangun hipothesis sebagai berikut:

\section{H1: Tingkat pengembalian operasi atas aset berpengaruh signifikan terhadap terjadinya underpricing pada saat IPO}

Kendala kecukupan informasi dalam pengambilan keputusan baik emiten yang melakukan IPO dan para investor potensial, mendorong kebutuhan pihak perantara keuangan, dalam hal ini perusahaan sekuritas yang memiliki ijin penjamin efek, untuk berperan menjembatani ketersediaan informasi sekaligus sebagai underwriter.

Perusahaan emiten yang melakukan IPO yang belum paham akan kondisi pasar akan membutuhkan pertimbangan dan analisis serta penjaminan atas aksi perusahaan yang melakukan IPO. Demikian 
pula di sisi investor potensial. Investor potensial hampir jarang yang memiliki informasi yang rinci dan komprehensif mengenai riwayat operasi perusahaan emiten yang akan melakukan IPO.

Harapan dari sisi emiten saat IPO bahwa harga saham mereka akan diapresiasi oleh pasar yang ditandai dengan adanya kenaikan harga saham sampai dengan akhir hari perdagangan pertama IPO (harga penutupan) (Loughran dan Ritter, 2002). Hal ini sejalan dengan signalling theory. Di sisi investor, harga saham yang cenderung menglami kenaikan merupakan sinyal bahwa perusahaan emiten yang sedang IPO adalah perusahaan yang bagus karena akan memberikan tambahan premium dari kepemilikannya. Kondisi ini mendorong underwriter berupaya memenuhi harapan kedua belah pihak dengan menerbitkan prospektus yang komprehensif (McDonald dan Fisher, 1972).

Keberhasilan underwriter dalam memenuhi harapan kedua belah pihak tersebut ditandai dari nilai intial return yang positif atau kondisi underpricing. Sehingga kondisi berimplikasi bahwa underpricing digunakan untuk menandakan kualitas underwriter (Dai, et al., 2014; Chen, et al., 2013; dan Welch, 1989). Kualitas underwriter merupakan reputasi bagi underwriter dalam memitigasi asimetri informasi antara emiten dan investor potensial (Chen, et al., 2013). Oleh karena itu, underwriter mendapatkan insetif dari asimetri informasi ini melalui penetapan harga IPO dan hak untuk alokasi saham baru (Mumtaz, et al., 2016 dan Loughran dan Ritter, 2002) melalui kondisi underpricing (Dai, et al., 2014).

Berdasarkan pertimbangan tersebut, penelitian ini menduga bahwa underwriter yang berreputasi cenderung akan berpotensi untuk mencapai kondisi underpricing. Sehingga, hipothesis yang dibangun adalah sebagai berikut:

\section{H2: Reputasi underwiter berpengaruh signifikan terhadap terjadinya underpricing pada saat IPO}

\section{METODE PENELITIAN}

Untuk menguji hipothesis dan melakukan analisis atas hasil pengujian hipothesis yang telah dibangun, maka model penelitian yang digunakan adalah model regresi liner berganda dengan variabel terikatnya adalah underpricing dan dua variabel bebas, yaitu reputasi underwriter dan return on assets. Sebelum melakukan pengujian, penelitian ini melakukan analisis statistik deskriptif dan uji asumsi klasik dalam rangka mendapatkan model regresi yang BLUE, yang sudah terbebas dari masalah heterokedastisitas dan multikolinearitas, serta autokorelasi.

$$
\mathrm{UP}=\alpha_{0}+\beta_{1} \mathrm{RU}+\beta_{2} \mathrm{ROA}+\varepsilon
$$

Keterangan: $\mathrm{UP}=$ Underpricing; $\mathrm{RU}=\mathrm{Reputasi}$ Underwriter; dan $\mathrm{ROA}=$ Return on Assets

Pengukuran underpricing menggunakan pengukuran yang digunakan pada Jogiyanto (2015), dimana tingkat underpricing dihitung dengan mencari initial return dari emiten yang melakukan IPO. Initial return adalah tingkat pengembalian yang didapat investor karena perbedaan harga saham yang dibeli di pasar perdana dengan harga jual saham yang bersangkutan di pasar sekunder. Sehingga, initial return dapat diperoleh dari selisih harga penutupan dengan harga penawaran, kemudian di bagi dengan harga penawaran.

Untuk pengukuran variabel bebasnya, Reputasi Underwriter adalah variabel dummy, dimana diberi nilai 1, apabila kategori underwriternya memiliki reputasi yang tinggi dan diberi nilai 0 untuk kategori underwriter lainnya. Kategori underwriter yang tinggi adalah underwriter yang 
termasuk dalam 10 besar pada 20 most active brokerage house monthly IDX berdasarkan total frekuensi perdagangan. Sementara untuk tingkat pengembalian atas aset menggunakan ukuran ROA (Mumtaz, et al., 2016), yang merupakan rasio laba setelah pajak terhadap total aset.

Data penelitian ini adalah data sekunder yang dikumpulkan dari website bursa efek Indonesia dan publikasi Laporan Keuangan emiten, serta informasi pasar yang dikeluarkan oleh Yahoo Finance. Objek dalam penelitian ini menggunakan populasi perusahaan yang melakukan initial public offering dan mengalami kondisi underpricing di Bursa Efek Indonesia selama periode amatan yaitu tahun 2015 sampai dengan 2019. Selama periode penelitian, terdapat 181 perusahaan, 12 perusahaan mengalami overpricing, 2 perusahaan tetap/konstan, dan 8 perusahaan merupakan perbankan yang akan dikeluarkan dari sample karena industri keuangan merupakan industri yang pengaturannya ketat dan berbeda, serta 75 perusahaan mengalami kerugian pada periode data penelitian sesuai dengan tujuan penelitian ini yang ingin melihat underpricing khusus pada perusahaan yang memang telah berkinerja baik (laba). Dengan demikian, total keseluruhan sampel yang digunakan dalam penelitian ini adalah sebanyak 84 perusahaan.

\section{PEMBAHASAN DAN HASIL}

\section{Hasil}

Setelah melakukan pengumpulan data, diperoleh sebaran data penelitian sebagai berikut:

\begin{tabular}{|l|c|c|c|}
\hline & UP & RU & ROA \\
\hline Mean & 0.4034 & NA & 0.0796 \\
\hline Median & 0.4956 & 0 & 0.0549 \\
\hline Maximum & 0.7100 & 1 & 0.2488 \\
\hline Minimum & 0.0045 & 0 & 0.0002 \\
\hline Std. Dev. & 0.2556 & NA & 0.0686 \\
\hline
\end{tabular}

\begin{tabular}{|l|c|c|c|}
\hline Modus & NA & 0 & NA \\
\hline
\end{tabular}

Tabel 1. Hasil Statistik Deskriptif Data Penelitian

Data tersebut kemudian ditelusuri lebih lanjut untuk mendeteksi apakah sudah terbebas dari masalah normalitas, heterokedastisitas, multikolinearitas, dan autokorelasi agar model regresi linear berganda yang digunakan untuk pengujian hipothesis tidak bias. Berikut hasil pengujian asumsi klasik yang dilakukan.

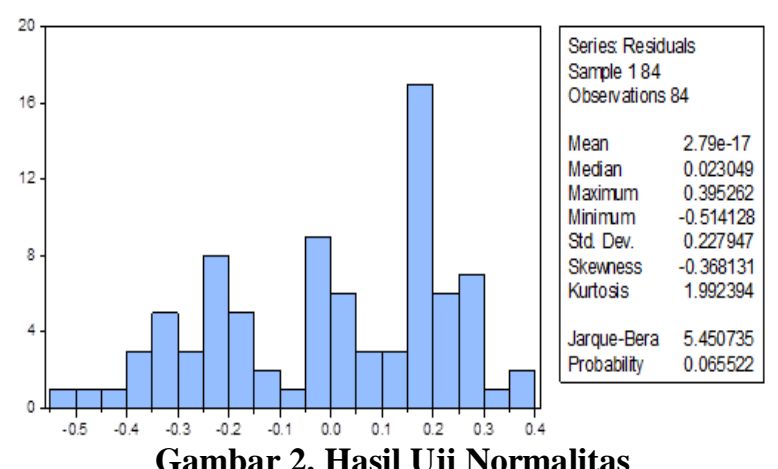

Hasil uji heterokedastisitas menggunakan Heteroskedasticity Test: White.

Dependent Variable: RESABS

Method: Least Squares

Sample: 184

Included observations: 84

\begin{tabular}{ccccc}
\hline \hline Variable & Coef-t & Std. Error & t-Statistic & Prob. \\
\hline \hline C & 0.164185 & 0.020221 & 8.119615 & 0.0000 \\
ROA & 0.248198 & 0.188683 & 1.315419 & 0.1921 \\
RU & 0.039650 & 0.029698 & 1.335090 & 0.1856 \\
\hline \hline R-squared & 0.048558 & Mean dependent var & 0.193856 \\
Adjusted R-squared & 0.025065 & S.D. dependent var & 0.118012 \\
F-statistic & 2.066954 & Durbin-Watson stat & 1.951271 \\
Prob(F-statistic) & 0.133195 & & & \\
\hline \hline
\end{tabular}

Tabel 2. Hasil Uji Heterokedastisitas 
Kemudian hasil uji multikolineritas ditunjukan pada Tabel 3 berikut:

Variance Inflation Factors

Sample: 184

Included observations: 84

\begin{tabular}{cccc}
\hline \hline Variable & $\begin{array}{c}\text { Coefficient } \\
\text { Variance }\end{array}$ & $\begin{array}{c}\text { Uncentered } \\
\text { VIF }\end{array}$ & $\begin{array}{c}\text { Centered } \\
\text { VIF }\end{array}$ \\
\hline \hline C & 0.001603 & 2.529571 & NA \\
ROA & 0.139605 & 2.418987 & 1.023100 \\
RU & 0.003459 & 1.364133 & 1.023100
\end{tabular}

Tabel 3. Hasil Uji Multikolinearitas

Selanjutnya, hasil uji autokorelasi ditunjukkan pada Tabel 4 berikut:

\begin{tabular}{|c|c|c|c|c|c|c|}
\hline $\mathrm{N}$ & DL & DU & $\begin{array}{c}\text { NILAI } \\
\text { DW }\end{array}$ & $4-\mathrm{DU}$ & $4-\mathrm{DL}$ & Keputusan \\
\hline 84 & 1.5245 & 1.7028 & 1.951271 & 2.2972 & 2.5755 & $\begin{array}{c}\text { Tidak terjadi } \\
\text { Autokorelasi }\end{array}$ \\
\hline
\end{tabular}

Tabel 4. Hasil Uji Autokorelasi

Setelah data penelitian sudah tidak mengandung masalah normalitas, heterokedastisitas, multikolinearitas, dan autokorelasi, maka pengujian regresi linear berganda dilakukan. Hasilnya adalah sebagai berikut:

Dependent Variable: UP

Method: Least Squares

Sample: 184

Included observations: 84

\begin{tabular}{lrlrl}
\hline \hline Variable & Coefficient & Std. Error & t-Statistic & Prob. \\
\hline \hline C & 0.531329 & 0.040042 & 13.26935 & 0.0000 \\
ROA & -1.010559 & 0.373637 & -2.704652 & 0.0083 \\
RU & -0.190092 & 0.058810 & -3.232319 & 0.0018 \\
\hline \hline R-squared & 0.204801 & Mean dependent var & 0.403356 \\
Adjusted R-squared & 0.185166 & S.D. dependent var & 0.255620 \\
F-statistic & 10.43065 & Durbin-Watson stat & 2.036307 \\
Prob(F-statistic) & 0.000093 & & & \\
\hline \hline
\end{tabular}

Tabel 5. Hasil Pengujian Hipothesis

\section{Pembahasan}

Berdasarkan 84 perusahaan sampel penelitian yang melakukan IPO selama periode 2015-2019, seperti pada ringkasan data pada Tabel 1, memperlihatkan tingkat initial return sebagai proksi dari underpricing maksimal hanya $71 \%$ dan tingkat underpricing paling rendah $0,045 \%$. Potret ini menggambarkan range tingkat underpricing yang sangat lebar dan bervariasi. Banyaknya perusahaan dengan tingkat underpricing yang rendah, di bawah nilai tengahnya yaitu sebesar 49,67\%, membuat rata-rata tingkat underpricing hanya sebesar 40,34\%. Artinya, emiten secara rata-rata memperoleh tingkat pengembalian (return) dari harga saham perdana yang ditawarkan pada hari IPO sebesar 40,34\%.

Sementara itu, ROA emiten yang melakukan IPO rata-rata sebesar $7,96 \%$, dengan ROA tertinggi hanya sebesar $24,88 \%$ dan yang terrendah sebesar $0,002 \%$ (kurang dari $1 \%$ ). Namun, dengan nilai tengah ROA sebesar $5,49 \%$ memperlihatkan bahwa perusahaan yang melakukan keputusan IPO cenderung memiliki kapasitas untuk menghasilkan laba dari operasi aset yang rendah. Kondisi inilah yang mendorong perusahaan untuk mencari dukungan ekuitas dari pasar modal. Selanjutnya, emiten yang menggunakan underwiter yang berreputasi hanya sebanyak 21 perusahaan, $25 \%$ dari sampel penelitian.

Kemudian, pada serangkaian hasil pengujian asumsi klasik yang bertujuan pengujian asumsi klasik adalah untuk memberikan suatu kepastian bahwa persamaan regresi yang didapatkan memiliki ketepatan dalam estimasi, tidak bias dan konsisten. Pengujian asumsi klasik diperlukan untuk mengetahui apakah hasil estimasi regresi yang dilakukan benar-benar bebas dari adanya gejala heteroskedastisitas, gejala multikolinearitas, dan gejala autokorelasi. Hasilnya pada Gambar 2 memperlihatkan dengan menggunakan uji klomogorov-smirnov, nilai probability Jarque-Bera sebesar 0.065522 lebih besar 
dari 0.05. Sehingga, disimpulkan bahwa error dari data variabel dalam penelitian ini telah terdistribusi normal. Kemudian, hasil uji heteroskedastisitas dengan metodi uji white pada Tabel 2 membuktikan nilai Prob. Chi Square sebesar 0,133195 lebih besar dari tingkat signifikan yang ditentukan yaitu 0,05 , yang berarti bahwa tidak terdapat gejala heterokedasitas.

$$
\text { Selanjutnya untuk uji }
$$

multikolinearitas dan autokorelasi, Tabel 3 memperlihatkan nilai Variance Inflation Factor (VIF) di bawah 10, yang berarti bahwa tidak terjadi korelasi yang tinggi diantara variabel bebas. Tabel 4 memperlihatkan hasil nilai DU sebesar 1.7028 lebih kecil dari Durbin Watson sebesar 1.951271 dan lebih kecil dari 4 dikurang nilai batas bawah (4DL) sebesar 2.5755. Sehingga, model pengujian terhindar dari autokorelasi naik positif maupun negatif, yang berarti bahwa model regresi linear tidak ada korelasi antara kesalahan pengganggu pada periode sekarang dengan kesalahan pengganggu pada periode sebelumnya.

Setelah memastikan data penelitian tidak mengandung masalah ekonometri, selanjutnya adalah hasil pengujian model penelitian. Pada tabel 4, model pengujian terbukti dapat dipergunakan sebagai model pengujian hipothesis dapat dibuktikan dari nilai Prob (F-statistic) sebesar 0.000093 yang lebih kecil dari 0.05. Kemudian, model pengujian dengan nilai R-squared sebesar 0.2048012 memberikan arti bahwa reputasi underwriter dan tingkat pengembalian atas aset dapat menjelaskan anomali underpricing sebesar $20,48 \%$.

\section{Pembahasan Hasil Pengujian Hipothesis}

Berdasarkan Tabel 4, semua hipothesis yang dibangun pada penelitian ini terbukti secara empiris terbukti signifikan. Pada hipothesis 1 yang menduga bahwa semakin tinggi tingkat pengembalian atas operasi aset yang diproksi dengan ROA berpengaruh signifikan terhadap underpricing, terbukti. Nilai Prob ROA sebesar 0,0083 yang lebih kecil dari 0,05 membuktikan secara signifikan ROA memberikan pengaruh negatif terhadap underpricing. Nilai koefisien regresi ROA bernilai negatif 1,010559 yang artinya ROA berpengaruh negatif terhadap underpricing. Setiap kenaikan satu persen keberhasilan perusahaan dalam menghasilkan laba dari operasi asetnya, akan memperkecil tingkat underpricing lebih dari $101 \%$ yang terjadi pada saat penawaran saham perdana. Hasil ini senada dengan temuan Djashan, (2017) dan Cornanic and Novak (2015).

Hasil ini mendukung fenomena dimana perusahaan yang memiliki tingkat laba dari hasil operasi aset yang relatif rendah masuk ke pasar modal untuk mencari tambahan modal dari publik (Gumanti, et al., 2017; Mumtaz, et al., 2016; Pennacchio, 2014; Loughran dan Ritter, 2002). Prospektus emiten dikemas untuk memberikan sinyal good news kepada calon investor meski tingkat keuntungan operasi aset rendah. Sejalan dengan theory signalling dan "lemon problem", perusahaan yang akan melakukan IPO akan berupaya untuk mengungkapkan laba atas operasi aset yang tinggi sebagai sinyal kinerja perusahaan yang dikelola baik untuk mendapatkan perhatian dan apresiasi positif dari investor potensial. Namun, asimetri informasi antara emiten dan investor potensial menjadi hal yang membuat investor potensial digiring untuk melihat dari sisi yang berbeda. Perusahaan akan mempromosikan bahwa meski laba atas operasi aset yang rendah justru memiliki peluang untuk bertumbuh lebih baik bila mendapat dukungan penambanhan ekuitas yang signifikan dengan menampilkan prospektus yang komprehensif (Mumtaz, et al., 2016).

Di sisi lain, karena perusahaan meghasilkan laba atas operasi aset yang 
rendah, hal ini dapat menjadi rujukan untuk penetapan harga saham perdana juga rendah. Sehingga, pada saat penutupan dan setelah investor potensial mempelajari prospektus perusahaan yang melakukan IPO, harga saham penutupannya menjadi positif, bahkan boleh jadi memiliki return positif yang range-nya panjang. Kondisi ini secara keseluruhan hasil hari pertama IPO menjadikan posisi perusahaan yang melakukan IPO pada underpricing.

Penyajian prospektus yang
komprehensif yang mencoba mengemas kondisi operasi perusahaan yang memiliki laba operasi atas aset yang rendah, namun dapat beroperasi dengan perputaran yang cepat (Loughran dan Ritter, 2002) ditambah dengan penetapan harga saham perdana yang juga dipatok rendah untuk menarik investor potensial, boleh jadi merupakan latar belakang hasil penelitian ini dalam mengungkap bagaimana laba atas operasi aset yang rendah justru dapat membuat perusahaan dalam kondisi underpricing pada saat IPO.

Selanjutnya, hipothesis 2 yang menduga reputasi underwriter berpengaruh signifikan terhadap kondisi underpricing, terbukti signifikan secara empiris berdasarkan nilai Prob RU 0,0018 yang lebih kecil dari 0,05. Dengan koefisien regresi bernilai negatif sebesar 0.190092 menunjukkan bahwa reputasi underwriter berpengaruh negatif terhadap underpricing pada penawaran perdana saham.

Underwriter berperan penting saat emiten melakukan penawaran saham di pasar perdana. Perusahaan ketika melakukan IPO perlu memperhatikan reputasi dari underwriter yang mereka pilih untuk membantunya dalam menawarkan saham ke publik agar tujuan awal perusahaan melakukan IPO yaitu mendapatkan dana yang maksimal dapat tercapai (Dai, et al., 2014 dan Chen, et al., 2013).
Dalam menghadapi IPO, investor potensial cenderung melihat terlebih dahulu pihak yang menjadi underwriter karena menurut investor, underwriter dianggap memiliki informasi yang lebih lengkap tentang kondisi emiten, begitu pula jika dibandingkan dengan emiten, underwriter dianggap memiliki informasi yang lebih lengkap tentang pasar. Artinya, semakin baik reputasi underwriter yang menangani IPO, maka semakin baik pula pengungkapan yang dilakukan perusahaan sehingga dapat mengurangi asimetri informasi yang mungkin terjadi antara investor dan emiten (Chen, et al., 2013). Oleh karena itu, perusahaan dapat mengurangi risiko terjadinya underpricing.

Dalam penelitian ini berhasil menunjukkan bahwa underwriter yang bereputasi tinggi akan mengurangi resiko ketidakpastian di masa yang akan datang. Hal ini berarti bahwa perusahaan yang dijamin oleh underwiter yang memilik reputasi baik pada saat IPO cenderung mengalami underpricing yang rendah pada saat perdagangan saham perdana di pasar sekunder. Alasan yang mendasar dalam hal ini adalah bahwa underwiter yang memiliki reputasi baik dan pengalaman sebelumnya akan memberikan estimasi yang baik pula dalam menaksir harga saham perdana sehingga kemampuan tersebut akan mendekati kondisi yang diharapkan oleh pasar. Dengan estimasi underwriter yang tepat maka permintaan dan penawaran saham perdana di pasar sekunder akan memperkecil tingkat underpricing saham perdana, dan calon investor bersedia membeli karena menggangap harga yang ditawarkan wajar dan pantas. Hasil ini memperkuat temuan Chhabra, et al. (2017). 


\section{KESIMPULAN}

Penelitian ini bertujuan untuk menyelidiki pengaruh tingkat pengembalian operasi atas aset dan reputasi underwriter terhadap underpricing pada saat IPO. Berdasarkan hasil pengujian hipothesis membuktikan bahwa ROA sebagai proksi dari tingkat pengembalian operasi aset dan reputasi underwriter terbukti berpengaruh negatif signifikan terhadap underpricing saat IPO.

Hasil penelitian ini memberikan implikasi secara praktik kepada perusahaan yang akan melakukan IPO dan investor potensial. Bagi perusahaan yang akan melakukan IPO, pemilihan underwriter yang berreputasi dapat membantu perusahaan dalam menetapkan harga saham perdana yang optimal. Sementara bagi investor potensial, hasil penelitian ini yang menunjukkan semakin besar tingkat pengembalian operasi aset, justru dapat memperkecil intial return pada kondisi underpricing, sehingga investor potensial perlu melakukan analisis fundamental yang memadai pada saat keputusan pembelian saham perusahaan IPO. IPO akan lebih berisiko dikaitkan dengan initial return yang lebih tinggi daripada yang rendah. Risikonya mencerminkan ketidakpastian valuasi karena investor mengalami kesulitan untuk mengestimasi nilai perusahaan. Sehingga, underpricing muncul sebagai kondisi ekuilibrium yang akan diinduksi investor untuk berpartisipasi dalam pasar IPO.

Meskipun hipothesis dari penelitian ini terbukti, namun terdapat beberapa kelemahan. Pengukuran underpricing dan ROA akan lebih baik bila menggunakan beberapa tingkat, melalui pengukuran kategorik, sehingga dapat diketahui secara lebih seksama pada tingkat ROA berapa yang harapkan investor potensial saat IPO. 


\section{DAFTAR PUSTAKA}

Afza, T., Yousaf, H., \& Alam, A. 2013. Information Asymmetry, corporate governance and IPO under-pricing. Science International (Lahore), 25(4), 989-997.

Akerlof, G.A. 1970. The market for 'Lemons': quality uncertainty and the market mechanism. Quarterly Journal of Economics. Vol. 84 No. 3, pp. 488500.

Beatty, R.P. and Ritter, J.R. 1986. Investment banking, reputation, and the underpricing of initial public offerings. Journal of Financial Economics, Vol. 15 No. 1, pp. 213-232.

Chhabra, S., Kiran, R., \& Sah, A. N. 2017. Information asymmetry leads to underpricing: validation through SEM for Indian IPOs, Program, 51, 116-131.

Chen, C., Shi, H. and Xu, H. 2013. Underwriter reputation, issuer ownership, and pre-IPO earnings management: evidence from China. Financial Management, Vol. 42 No. 3, pp. 647-677.

Cornanic, A., and Novak, J. 2015. Signaling by underpricing the initial public offerings of primary listings in an emerging market. Finance a Uver, 65, 307-335. doi:10.2139/ssrn. 2273470

Dai, Y.Y., Pan, Y. and Chen, J. 2014. Dual sponsors' reputation, social trust and IPO approval. Journal of Financial Research, No. 6, pp. 146-161

Djashan, I. A. 2017. Analisis Faktor-Faktor Terhadap Underpricing Saham Perdana. Jurnal Bisnis Dan Akuntansi, 19(2), 251-258.

https://doi.org/10.34208/jba.v19i2.277

Gumanti, T. A., Lestari, A. R., \& Mannan, S. A. 2017. Underpricing and number of risk factors of initial public offerings in Indonesia. Business: Theory \&
Printed ISSN : 2406-7415

Elektronik ISSN : 2655-9919 Jurnal Akuntansi dan Bisnis Krisnadwipayana Volume 9 Nomor 1 (Januari - April) 2022

Practice, 18 , 178-185. doi:10.3846/btp.2017.019

Jensen and Meckling. 1976. Theory of the Firm. Managerial Behavior, Agency Cost and Ownership Structure. Journal of Financial Economic.

Jogiyanto, H. M. 2015. Teori Portofolio dan Analisis Investasi. BPFE

Leland, H. E., \& Pyle, D. H. 1977. Informational asymmetries, financial structure, and financial intermediation. The Journal of Finance, 32(2), 371387.

Loughran, T., \& Ritter, J. R. 2002. Why don't issuers get upset about leaving money on the table in IPOs? Review of Financial Studies, 15(2), 413-443.

Loughran, T., \& McDonald, B. 2013. IPO First-Day Returns, Offer Price Revisions, Volatility and Form S-1 Language. Journal of Financial Economics, 109(2), 307-326.

Lowry, M., Michaely, R. and Volkova, E. 2017. Initial public offering: a synthesis of the literature and directions for future research. https://papers.ssrn.com/sol3/papers.cf m?abstract $\mathrm{id}=2912354$

McDonald, J. G., \& Fisher, A. K. 1972. New issue stock price behaviour. Journal of Finance, 3(1).

Mumtaz, Muhammad Zubair, Zachary A. Smith and Ather Maqsood Ahmed. 2016. An Examination of short-run performance of IPOs using Extreme Bounds Analysis. Estudios de Economia. Vol.43-No.1 Junio 71-95.

Moshirian, F., Ng, D. \& Wu, E. 2010. Model specification and IPO performance: New insights from Asia. Research in International Business and Finance, Vol. 24; 62-74.

Pennacchio L. 2014. The Causal Effect of Venture Capital Backing on the Underpricing of Italian Initial Public 
Printed ISSN : 2406-7415 Elektronik ISSN : 2655-9919 Jurnal Akuntansi dan Bisnis Krisnadwipayana

Offerings. Venture Capital, Vol. 16, No. 2, pp. 131-155.

Reiche, O. 2015. The Phenomenon of IPO Underpricing in the European and U.S. Stock Markets. Anchor Academic
Publishing.

https://doi.org/3954897954

Rock, K. 1986. Why new issues are underpriced? Journal of Financial Economics, Vol. 15 Nos 1/2, pp. 187212. 